Leakey, who assigned to each of these women a species of great ape. (Actually, we are told, Leakey gave Galdikas a choice: she could have had the pygmy chimpanzee or bonobo, but she stuck to the Asian ape.) Leakey's influence as the 'spiritual father' of these scientific siblings is immense and pervasive: much of the final, summing-up chapter is a synthesis of Galdikas's feelings about her 'sisters'. As the youngest offspring, Galdikas seems to be the most keen to uphold Leakey's memory, perhaps because he died before she achieved success.

Unlike the books by her fellow trimates, Reflections of Eden is highly egocentric, sometimes frustratingly so. Of the 64 photographs, 37 feature Galdikas, whereas only 36 portray orangutans. (Oddly enough, there is no photograph of the forest itself, despite the book's title.) No references are given should the reader want to pursue Galdikas's scientific writing or the alternative views of others. There is no index, and most of the 22 chapters have enigmatic one-word titles, usually proper names. Chronologically, the book concentrates on the first four years of the project - as late as Chapter 16, we have reached only 1975.

The substance of the book is a memoir of what it is like to study wild orangutans and to live with ex-captive orangutans who have been confiscated and then released back into the wild. Following Goodall's and Fossey's lead, Galdikas concentrates on individual apes, about half from each category. Here Galdikas is at her best. She is a master storyteller: vivid, evocative, moving. In delving into the hearts and minds of her subjects, she is intuitively persuasive. (Interestingly, unlike most field primatologists, her undergraduate major was in psychology.)

Underlying the account is a spiritual theme that goes beyond the recurring imagery of Eden. God features prominently, most startlingly as a super-hominoid player of cat's cradle. A walk into the rainforest is likened to a walk into the mind of God. Angels keep popping up, either as wealthy donors in Los Angeles or as self-descriptors for the trio, with, for example, Fossey's anti-poaching efforts making her an avenging angel. Galdikas tells us that her revelationary calling came in the form of a crystal-clear chime during a lecture at the University of California, Los Angeles. So it is not surprising that the book's final sentence reads: "We are allowed to see the eyes of God [when we look into the eyes of an orangutan]".

Happily, the scientific findings after decades of research are notable. Orangutans really are loners: Galdikas has never seen two adult females groom one another - and they are reckoned to be the more sociable of the two sexes! Males disperse from their natal ranges, whereas females stay at home, making the Asian ape different from its African cousins. The typical birth interval is eight years, the longest of any species of primate. Despite the remarkable ingenuity and imitational skills of released captive orangutans, such as their attempts to kindle cooking fires, their wild counterparts show no subsistence technology whatsoever. They regularly mate face to face and engage in forcible copulation, which Galdikas likens to "date-rape".

Unfortunately, knowledge from her impressive research is rarely integrated with that of others. Of her contemporaries, only John MacKinnon is credited. Pioneers such as Peter Rodman and David Horr are mentioned only to be dismissed, and decades of research by Dutch workers such as Hermann Rijksen on the other subspecies of orangutan in Sumatra are simply ignored. Japanese researchers (Akira Suzuki, for example) and Indonesian researchers (such as Jito Sugardjito) suffer a similar fate. Galdikas may well have spent more time near wild orangutans than all other primatologists put together, but science is not a solitary activity, even when its subjects are.

The strengths and weaknesses of the book ultimately boil down to one basic difference between Galdikas and her counterparts, Fossey and Goodall. Unlike them,
Galdikas undertook to do both research and conservation from the beginning. Within a week of arriving in Borneo, she instigated the rescue of a pet orangutan and so began a commitment to individual welfare that persists to this day. Her field site, Camp Leakey, is thick with excaptives, from panhandlers to irregulars. Rehabilitation of infant great apes is a round-the-clock job, exhausting in all ways. To have done it in parallel with full-time study of wild primates is unprecedented, like holding down two jobs, each of which could be all-consuming. This double life has taken a toll along with the rewards: at no point does Galdikas seriously address the key issue of the possible impact of her immigrants on the lives of the wild resident apes. More than a hundred incomers have been released into what was apparently an ecosystem already at carrying capacity, yet she fails to consider the consequences of enhanced competition. At the end of the book, one wishes it were two, one about the natural lives of our close relations and another about the challenges and choices of repairing our human mistreatment of those same cousins.

W. C. McGrew is in the Departments of Anthropology and Zoology, Miami University, Oxford, Ohio 45056, USA.

\title{
A river runs through it
}

\section{Christopher Wills}

River Out of Eden: A Darwinian View of Llfe. By Richard Dawkins. BasicBooks/Weidenfeld and Nicolson. Pp. 166. \$20, £9.99.

THIS short book is the latest in the Science Masters series, a set of brief explorations of their fields of expertise by some of today's most distinguished science writers. Richard Dawkins treats the subject of evolution in his usual limpid style. The book breaks no new ground but, as usual, it abounds with metaphors that make things brilliantly clear. As someone in the metaphor business myself, I must admit that nobody can turn a metaphor better than Dawkins. The central metaphor here is that evolution is like a river, flowing smoothly (more about this later) and made up not of water but of bits of digital information. We are rapidly moving into a digital world, and Dawkins, no laggard, points out that it is lucky that our genetic material is digital rather than analogue.

It is not impossible to imagine an analogue mechanism for passing genetic information from one generation to the next. Suppose a gene were to consist of a protein molecule of a specific shape, which serves as a template for the construction of another protein containing a negative image of it. This in turn would serve as a template for the construction of a molecule of roughly the original shape, and then the process would be repeated. It would not take many generations before the genetic message would fade into indecipherability. And, although Dawkins does not make the point, that is how geneticists tended to think about gene replication before the age of Watson and Crick.

I immediately tried out Dawkins's picture of a flow of digital information on students in my class on molecular evolution. Most of them, it turned out, knew all about digital information, but few had come across the concept of analogue information. (Those who want to use his image had better hurry, before the memory of analogue watches and analogue records fades from the collective consciousness.) Dawkins uses the metaphor of a digital river to link together lucid discussions of several fairly disparate subjects: the provenance of the mitochondrial Eve, the way in which complex organs and behaviours might have evolved and the problem of good and evil. His view of the last will be, for many potential readers, a bone-chilling one: 
"The universe we observe has precisely the properties we should expect if there is, at bottom, no design, no purpose, no evil and no good, nothing but blind pitiless indifference. ... DNA neither knows nor cares. DNA just is. And we dance to its music."

This is a bit too remote. It is the dance, of course, that is important to us. It produces events that, if not good or evil, are certainly excellent imitations. There is also a certain remoteness about Dawkins's metaphor of a river. His image of a digital river is, it would seem, coloured by his experience of the well-tamed genteel rivers of the English countryside. There are no rapids to roil the flow, no chasms and sudden changes of direction. Yet it is becoming increasingly apparent that dramatic events can happen to the digital river, and it would have been exciting if he had explored some of them.

$\mathrm{He}$ goes too far in rejecting the claims of the proponents of punctuated equilibrium.

Even though the idea as originally proposed had no mechanism attached to it, more and more mechanisms are being found that can speed up and slow down evolution. Walter Gehring and his collaborators can make compound eyes appear all over the body of a fruitfly, like a rash. This tells us something about the capability of a fly's genome to do startling things, a capability that is already present and that Gehring can tap into.

The book, although an excellent introduction to many important evolutionary ideas, slightly suffers because of Dawkins's reluctance to discuss some of these fascinating recent breakthroughs. Had he done so, the river that emerged might not have been so limpid but it could have provided a wilder ride.

Christopher Wills is in the Department of Biology, University of California, San Diego, La Jolla, California 92093-0116. USA.

\section{Emerging new science}

Ian Stewart

Thinking in Complexity: The Complex Dynamics of Matter, Mind, and Mankind. By Klaus Mainzer. Springer: 1994. Pp. 329. DM58, \$58, £23.

SyNERGETICS, non-equilibrium thermodynamics, catastrophe, symmetrybreaking, chaos, fractals, self-organized criticality, antichaos, complexity. ... For as long as I can remember, small bands of scientists led by maverick gurus have chopped away at their own little corners of a big problem - the occurrence of complex structures in what ought to be a simple Universe. One of their common themes has been the emergence of "collective phenomena', the insistence that the whole is not so much greater than the sum of its parts as different from it.

The deeper theme, however, is nonlinearity. Huge areas of traditional science are based on linear thinking, often without explicitly recognizing it. Classical population genetics, for example, is linear: it models a population as a homogeneously mixed pool of genes and studies only the proportions of particular genes. It is a 'mean field' theory that bases its entire conceptual armoury on a convenient fiction. Traditional mathematical economics is also relentlessly linear in viewpoint because of its emphasis on equilibrium behaviour and a onedimensional additive measure of value. An instructive example of the sheer vapidity of this way of thinking is a recent comparison of the cost of global warming with the cost of preventing it, carried out by the Intergovernmental Panel on
Climate Change (IPCC). Among other remarkable assumptions, the study valued the life of a European at ten times that of the life of an Asian, concluding although not in quite these words - that it makes economic sense to let Bangladesh sink beneath the waves to avoid minor discomfort in England.

There are many places where linear thinking works well, otherwise it would not have survived, but a cruel irony has led to its widespread adoption in many areas where it does not. Scientists reasonably work with what tools they have to build the biggest edifices they can manage. Linear mathematics is easy, whereas nonlinear mathematics was - at least until recently - impossible. So scientists erected overblown monuments to linear thinking, blissfully unaware that nature is largely nonlinear.

The times, they are a-changing. Nonlinear modelling is one of the biggest growth areas in the whole of science. To those of linear upbringing it may seem undisciplined - and it is, but only in the sense of its "not belonging to any particular discipline'. It is an irreducibly interdisciplinary way of thinking and it slices the cake of science in totally new directions.

Klaus Mainzer argues the case in favour of nonlinear thinking across the scientific board, from quantum mechanics to human society. $\mathrm{He}$ is unusually strong on history, taking care to place each argument in its proper historical context. This is an effective technique, driving home the fact that nonlinear methodology has its roots in ancient debates about matter, life and the mind.
Our deepest theory of matter, quantum mechanics, is linear - indeed it is probably the most spectacularly successful linear theory we have ever had - but the process that turns a quantum system into a classical measurement is manifestly not. So something nonlinear is going on, which cannot be captured by Copenhagen-style special pleading about collapsing wave functions.

Life poses irreducible problems for linear thinking. If one crushed all living creatures together with a huge mortar and pestle, the resulting chemical mix would show few of the characteristics of life (although it would mimic a linear 'gene pool' superbly). Life is a nonlinear process of increasing complexity, explicable in terms of dissipative selforganization.

With regard to the mind-brain problem, Mainzer has little time for either Descartes or Penrose. His approach is best summed up by a direct quotation: "The emergence of mental states. . . is explained by the evolution of (macroscopic) order parameters of cerebral assemblies which are caused by nonlinear (microscopic) interactions of neural cells in learning strategies far from thermal equilibrium". This thesis is developed in greater detail in the ensuing discussion of artificial intelligence and the selforganizing and learning abilities of neural nets.

Finally we come to the problem of political, social and economic order in human society. Linear thinking views these things in mean-field terms, for example in concepts such as 'the inflation rate' and 'the unemployment rate'. Note those 'the's'. In a real economy, individuals suffer their own variable inflation rate and their own even more variable unemployment rate. The macro-variables are emergent features of a complex system of millions of interacting agents, each with its own microvariables. In a classical linear economy, stock markets never crash.

All very well, but what should we actually do? The epilogue has some suggestions. Mainly they are to recognize the interdependence of systems that we usually try to keep separate (such as economics and the environment) and to accept that complex systems develop emergent properties - in short, to stop thinking linearly. Nonlinearity is not a universal answer, but it is often a better way of thinking about the problem. It is certainly better than the linear thinking that led the IPCC to conclude - no doubt without realizing it - that it makes sense to let nine Asians die in order to keep one European alive.

Ian Stewart is at the Mathematics Institute, University of Warwick, Coventry CV4 7AL, UK.

NATURE · VOL $374 \cdot 27$ APRIL 1995 